\title{
A importância da formação superior em pedagogia bilíngue para a educação de surdos
}

\author{
Carolina Carvalho Palomo Fernandes ${ }^{1}$
}

\begin{abstract}
RESUMO: Este artigo tem como objetivo geral analisar as contribuições da Pedagogia Bilíngue para a educação de surdos, observando a necessidade de profissionais com formação superior que responda às especificidades dos alunos surdos. É parte da pesquisa conhecer o sujeito surdo, suas peculiaridades e dificuldades. Destaca que para que os problemas enfrentados pelos alunos surdos se solucionem é preciso de profissionais que tenham conhecimentos coerentes com as exigências da área. Para isso, a pesquisa compara a grade curricular dos cursos de graduação de Pedagogia e Letras/Libras. Além disso o artigo discute sobre a graduação em Pedagogia Bilíngue. 0 artigo se constitui como uma pesquisa exploratória de cunho bibliográfico, da qual coletará e analisará os dados coletados. Conclui que é necessária a Pedagogia Bilíngue para que a educação de surdos se concretize com qualidade e acesso para todos.
\end{abstract}

Palavras-chave: Pedagogia Bilíngue. Educação de Surdos. Letras/Libras

\section{The importance of higher education in bilingual education for the education of the deaf}

\begin{abstract}
This article has as general objective to analyze the contributions of the Bilingual Pedagogy for the education of the deaf, observing the need for professionals with higher education that responds to the specifics of deaf students. It is part of the research to know the deaf subject, his peculiarities and difficulties. It emphasizes that for the problems faced by the deaf students to be solved it is necessary of professionals who have knowledge coherent with the exigencies of the area. For this, the research compares the curricular grade of the graduation courses of Pedagogy and Letters / Pounds. In addition the article discusses the graduation in Bilingual Pedagogy. The article is an exploratory research of a bibliographic nature, from which it will collect and analyze the data collected. It concludes that Bilingual Education is necessary for the education of the deaf to be concretized with quality and access for all.
\end{abstract}

Keywords: Bilingual Pedagogy. Education of the Deaf. Letters / Pounds

- Enviado em 08/08/2016

- Aprovado em 15/10/2016

\footnotetext{
${ }^{1}$ Graduada em Pedagogia pela Universidade Federal do Paraná (UFPR). Especialista em Educação Bilingue pelo IPE. E-mail: carolinacpfernandes@icloud.com
} 


\section{INTRODUÇÃO}

As motivações que levaram a elaborar este artigo advêm das dificuldades encontradas pela comunidade surda no que refere à educação. Em muitas instituições de ensino não há preparo profissional e recursos para atender às especificidades desta comunidade. Dessa forma, os surdos se deparam com muitas barreiras na comunicação e na compreensão do conteúdo ensinado e, muitas vezes, se sentem excluídos mesmo dentro de uma escola dita como "inclusiva". Não basta apenas inserir o surdo em uma turma de ouvintes. É preciso que o profissional saiba e entenda quais mudanças e estratégias serão necessárias para que o processo educacional aconteça de forma satisfatória e qualitativa. Estas mudanças, estratégias e especificidades da comunidade surda devem ser conhecidas e compreendidas durante a formação superior do profissional.

Diante desta situação, temos a Pedagogia Bilíngue como uma possível solução. Antes de afirmar se é a solução ideal, é necessário refletirmos acerca desta questão: De que forma a Pedagogia Bilíngue pode contribuir positivamente para a educação de surdos? Este tema decorre de questões levantadas ao longo da formação acadêmica na graduação em Pedagogia e no curso de pós-graduação lato sensu em Educação Especial: Educação Bilíngue para Surdos - LIBRAS/ Língua Portuguesa, quando se observou a ênfase que a graduação em Pedagogia dá à didática e às metodologias e a graduação em Letras/LIBRAS dá à história do surdo, sua identidade, cultura e língua, mas sem haver uma graduação que leve em conta os dois destaques simultaneamente. Assim, surgiram estas reflexões sobre as possíveis contribuições da Pedagogia Bilíngue para a educação de crianças, jovens e adultos surdos.

Sabemos que a educação de surdos exige conhecimentos, metodologias e materiais específicos à esta área e por isso a junção de aspectos da Pedagogia e de Letras/ LIBRAS resultaria na Pedagogia Bilíngue, formação superior que pode solucionar muitos destes problemas. Esta pesquisa analisará os aportes da Pedagogia Bilíngue para a educação de surdos, além de suscitar novas pesquisas e aprofundamentos sobre o tema.

De acordo com Gil (2007), as pesquisas são classificadas com base no objetivo geral e no delineamento a ser utilizado. Esta classificação de projeto de pesquisa assume as 
definições da pesquisa exploratória, visando o aprimoramento de ideias e oferecendo "maior familiaridade com problema, com vistas a torná-lo mais explícito [...]" (GIL, 2007, p. 41). Dessa forma, este artigo de pesquisa utilizará a pesquisa bibliográfica como procedimento técnico de coleta e análise de dados. A revisão bibliográfica auxiliará no esclarecimento sobre o sujeito surdo, suas necessidades de aprendizagens e as disciplinas de graduação em Pedagogia e Letras/LIBRAS. A revisão bibliográfica foi realizada mediante uma leitura sistemática com fichamento de cada obra, de modo a ressaltar os principais pontos da pesquisa dos autores.

\section{O SER SURDO E SUAS ESPECIFICIDADES}

Antes de tudo, é preciso compreender a definição de ser surdo. Sabemos que este termo refere às pessoas com perda auditiva, mas também há outros termos para se referir a essas pessoas. Muitas vezes há conflitos com os termos: deficiente auditivo, surdo-mudo e surdo.

A concepção clínica utiliza o termo "deficiente auditivo", ou seja, pessoa "com déficit sensorial-auditivo, que precisa ser compensado pela recuperação da audição, da estimulação auditiva para que tenha acesso à língua oral e se comunique pela fala, pois é considerada a única forma de comunicação e interação social” (CORMEDI, 2011, p. 7). Este termo é bastante utilizado e algumas das pessoas com perda auditiva não estão em concordância, pois a fala não é a única forma de comunicação e não há obrigatoriedade em recuperar e estimular a audição por meio de recursos cirúrgicos, adaptação de aparelho de amplificação sonoro ou de implante coclear para que possa haver a interação social.

A segunda expressão também usada é "surdo-mudo" ou "mudinho" transmite uma visão preconceituosa e equivocada. "Os surdos não são mudos, apenas não falam porque não ouvem, mas têm o aparelho fonoarticulatório em plenas condições de funcionamento 
para a produção vocal, se for o caso" (FERNANDES, 2011, p.20). Aqueles que escolhem a oralidade podem receber serviços de reabilitação oral e desenvolver a fala. Portanto, além de ser considerado por algumas pessoas como uma ofensa, este termo também não está correto para se referir às pessoas com perda auditiva.

Diante destes dois termos inadequados, a comunidade surda passou a combatê-los. As pessoas surdas se consideram como diferentes, mas não como deficientes. Diferente se refere na questão perceptual, afinal ela se dá pela modalidade visual, assim como a comunicação. 0 segundo termo também foi ignorado pelos surdos por ser totalmente equivocado e não considerar a Língua de Sinais como uma outra forma de comunicação. A pessoa com perda auditiva, considerando o seu direito de acesso à língua natural (Língua de Sinais), passou a utilizar o termo "surdo". Este termo está mais marcado pelo sócio-cultural da surdez, ou seja, o surdo "desenvolve potencialidades psicoculturais diferentes das dos ouvintes. " (BEHARES, 2000, p. 2). A identidade e a cultura que os surdos desenvolvem são especificas desta comunidade e se diferenciam dos ouvintes.

Os estudos de Strobel (2009, p.27), define a cultura surda como:

[...] o jeito surdo entender o mundo e de modifica-lo a fim de se torna-lo acessível e habitável ajustando-os com as suas percepções visuais, que contribuem para a definição das identidades surdas e das "almas" dascomunidades surdas. Isto significa que abrange a língua, as ideias, as crenças, os costumes e os hábitos do povo surdo.

Para que a identidade e cultura surda se configurem é preciso da presença de uma língua. As comunidades surdas têm como sua língua natural as línguas de sinais. De acordo com Quadros e Karnopp (2004, p. 30), entende-se por língua natural:

[...] uma realização específica da faculdade de linguagem que se dicotomiza em um sistema abstrato de regras finitas, as quais permitem a produção de um número 
ilimitado de frases. Além disso, a utilização efetiva desse sistema, com fim social, permite a comunicação entre os seus usuários.

As Línguas de Sinais são sistemas linguísticos complexos e bem estruturados como qualquer outra língua e é utilizado para facilitar a comunidade entre os surdos por utilizar a modalidade espaço-visual, não sendo necessário a audição ou a fala. Ao dizer que as Línguas de Sinais são gestos e mímicas estamos assumindo uma visão equivocada sobre elas, pois as mesmas são línguas como qualquer outra; composta de aspectos fonológicos, morfológicos, sintáticos e semânticos próprios. Assim, a língua de sinais é um "[...] instrumento cultural de uma comunidade capaz de atribuir uma identidade à pessoa surda que pode atuar como sujeito social com diferentes papéis dentro do grupo a que pertence (CORMEDI, 2011, p. 65). " A língua é adquirida pelas interações sociais e culturais e portanto é por meio dela que constitui a identidade do surdo.

Na interpretação de Damázio (2007, p. 21):

\begin{abstract}
As práticas pedagógicas constituem o maior problema na escolarização das pessoas com surdez. Torna-se urgente, repensar essas práticas para que os alunos com surdez, não acreditem que suas dificuldades para o domínio da leitura e da escrita são advindas dos limites que a surdez lhes impõe, mas principalmente pelas metodologias adotadas para ensiná-los.
\end{abstract}

Faz-se urgente rever as metodologias utilizadas e pensar numa estratégia de ensino que leve em conta estas especificidades comentadas para que a aprendizagem do aluno seja significativa.

Skliar (2001) explica que nas últimas três décadas, houve mudanças significativas na educação dos surdos, seja nas concepções ou seja na organização educacional e escolas e agora há maior consideração pela língua de sinais como primeira língua, discussão sobre as didáticas em relação a segundas línguas, mudanças no currículo escolar, presença de instrutores surdos nas escolas, entre outros. 
Apesar de haver polêmicas e opiniões divergentes sobre a educação mais "adequada" aos surdos, atualmente o Bilinguismo está no centro do cenário da educação brasileira. Podemos compreender, com base em Capovilla e Raphael (2001, p. 1486) que “ [...] no bilinguismo o objetivo é levar o surdo a desenvolver habilidades, primeiramente em sua língua natural e, subsequentemente, na língua escrita do país a que pertence. " Ali não preza apenas o respeito às especificidades relacionadas a comunicação dos surdos, mas o bilinguismo também oferece ao surdo o contato com seus pares. Os pesquisadores Lopes (2005) e Strobel (2009) defendem que este contato é essencial porque através dele o surdo aprende a ser surdo, ou seja, identifica com seus iguais, apropria de sua língua e ingressa na sua cultura.

Com relação à organização escolar, o bilinguismo impõe a mediação de diferentes profissionais no atendimento especializado, tais como Fernandes (2011, p. 105-106 grifo nosso) cita:

Professor ou instrutor de Libras - Profissional, preferencialmente Surdo, com graduação em Letras (Libras ou Letras Libras/ Língua Portuguesa) ou com formação em nível médio e/ ou superior com certificado de proficiência linguística em Libras emitido pelo Ministério da Educação - MEC (Prolibras). Professor bilíngue Professor com fluência em Libras que desenvolverá o ensino do português escrito com base em metodologias de ensino de segunda língua.

Profissional intérprete de Libras/ Língua Portuguesa - Profissional ouvinte que atua na mediação linguística do processo educacional de alunos Surdos matriculados no contexto regular de ensino, com graduação em

Tradução e Interpretação em Libras/ Língua Portuguesa; ou com formação em nível médio e/ou superior com certificado de proficiência em tradução e interpretação em Libras/ Língua Portuguesa (Prolibras) emitido pelo MEC.

Fonoaudiólogo bilíngue - Profissional responsável pelas práticas

terapêuticas de ensino do português oral, em turno distinto da escolarização, caso seja opção do aluno ou da família essa modalidade de língua. A ação desse profissional depende de políticas de interface entre as áreas de saúde e educação. 
Esses profissionais são importantes para que o bilinguismo aconteça efetivamente, mas são apenas uma parte do todo. Os profissionais auxiliaram na implantação de propostas de educação bilíngue e para isso exige reflexão sobre os conteúdos, objetivos, metodologias e formas de avaliação em curso na escola e sua adequação às possibilidades dos alunos Surdos. Para isso é necessário que o profissional caso seja ouvinte seja fluente em língua de sinais para que não sinalize na estrutura linguística do Português ou mescle as duas línguas e caso o profissional seja surdo, ele tenha conhecimento da Língua Portuguesa. Surge então a necessidade de preparar professores e profissionais para que possa contribuir na educação de surdos.

\section{A FORMAÇÃO SUPERIOR EM PEDAGOGIA E A FORMAÇÃO SUPERIOR EM LETRAS/LIBRAS: SEMELHANÇAS E DIFERENÇAS}

Para que o bilinguismo possa estar presente em instituições escolares é preciso que haja profissionais capacitados e com formação específica para esta área. Visando refletir sobre a Pedagogia Bilíngue, segue apresentação dos currículos (ingressantes a partir de 1990) da graduação em Pedagogia da Universidade Federal de Santa Catarina (UFSC) e da graduação em Letras / Libras Licenciatura da Universidade Federal de Santa Catarina (UFSC) retirado do site da universidade (ver quadro ao final do artigo).

Ao observar o currículo de ambas as graduações, é possível verificar primeiramente muitas disciplinas distintas; afinal a ênfase dada aos conhecimentos em cada curso é diferente. Claro que é há também algumas disciplinas em comuns, tais como a História da Educação em Pedagogia e a História da Educação de Surdos em Letras/Libras, Sociologia da Educação em Pedagogia e Sociolinguística em Letras/Libras, Psicologia da Educação em Pedagogia e Psicolinguística em Letras/Libras, Didática em Pedagogia e Didática e Educação de Surdos em Letras/Libras e a Língua Brasileira de Sinais em ambas os cursos de graduação. 
Cada curso de graduação possui as suas especificidades e antes de pensar na Pedagogia Bilíngue como uma junção de conhecimentos da Pedagogia e de Letras/Libras é preciso rever essas especificidades. Uma abordagem ao trabalho do profissional de Pedagogia deve levar em conta os comentários de Scheibe (2007, p. 44):

O Curso de Pedagogia destina-se, na sua atual formulação legal, à formação de professores para a educação infantil e os anos iniciais do ensino fundamental. Complementarmente, também ao desenvolvimento de competências para o ensino nos cursos de nível médio, na modalidade normal; ao ensino na educação profissional na área de serviços e apoio escolar; às atividades de organização e gestão educacionais; e às atividades de produção e difusão do conhecimento científico-tecnológico do campo educacional.

Vale lembrar aqui que este profissional mesmo com todas essas competências pode se deparar também com crianças, jovens e adultos surdos. Ainda mais se este profissional for defensor da educação bilíngue é preciso também de outros conhecimentos e estes voltados para a área da educação de surdos.

Já o curso de Letras/Libras possui outro foco como a Universidade Federal de Santa Catarina (2015) afirma em seu site:

No Curso de Letras/Libras o aluno estuda a língua, a literatura e a cultura da comunidade surda do Brasil e de outros países. Sua formação deverá ser direcionada já no ato de inscrição, momento em que o aluno deve optar por Licenciatura, caso queira atuar no ensino, ou pelo Bacharelado, caso queira atuar como tradutor/intérprete. [...] 0 profissional formado em Licenciatura em Letras/Libras poderá lecionar como professor de libras como primeira língua para surdos nos ensinos fundamental e médio, ou como professor de libras como segunda língua para ouvintes desde o nível fundamental até o nível superior de ensino (em particular, nos cursos de licenciatura de todo o país, que agora passarão a oferecer aulas de libras, tal como previsto no Decreto no 5626 ). Além disso, o professor de libras poderá também atuar em instituições especializadas no ensino da libras, como por exemplo federações e associações de surdos.

Neste curso há muita ênfase nos conhecimentos voltados para área da surdez, mas percebe-se que os aspectos educacionais como metodologia, recursos didáticos e 
teorias educacionais não são muito valorizados. Claro que os conhecimentos voltados para a área da surdez são essenciais dentro da educação de surdos, apenas não podemos esquecer que os aspectos pedagó gicos também são exigidos.

Diante desta realidade, nos aparece a Pedagogia Bilíngue como uma possível solução para os problemas relacionados à formação do profissional da educação de surdos e este necessita de conhecimentos tanto da graduação em Pedagogia quanto da graduação em Letras/Libras.

\section{A PEDAGOGIA BILÍNGUE PARA A EDUCAÇÃo DE SURDOS}

É importante ressaltar os argumentos de Nascimento e Costa (2014, p.161) no que se refere ao direito à educação:

\footnotetext{
Cada indivíduo deve ter garantido o seu direito inalienável à educação sendo respeitadas suas especificidades e necessidades, seu direito de ir, vir, estar e expressar-se onde se sente melhor. Assim, diante do universo diverso no qual encontram-se as mais diferentes pessoas, oferecer a educação de qualidade a todos não pode significar oferecer a mesma educação a todos.
}

Educação de qualidade para todos não é sinônimo de educação igual para todos. A educação oferecida aos alunos ouvintes não é uma educação que respeite os direitos dos surdos. Os surdos merecem e necessitam de uma educação que respeite suas especificidades e necessidades e dentro desta educação faz-se essencial a presença de profissionais qualificados e adequadas à esta educação.

Nascimento e Costa (2014, p.161) também destacam que: 
Os espaços educacionais específicos para o ensino, conforme proposto pela comunidade surda brasileira, exigem uma mudança abrupta de paradigma; muda-se o foco educacional da audição ausente na orelha do surdo para a competência linguística e para o potencial cognitivo que o surdo tem; o que significa oferecer a oportunidade de acesso real e concreto a todo tipo de conhecimento construído e alcançado pelo ser humano. Em síntese, a escola bilíngue erguida sobre os princípios norteadores na proposta que ora se apresenta tem como consequência a verdadeira inclusão dos surdos na sociedade.

A Pedagogia Bilíngue se mostra como a graduação mais adequada e coerente com as exigências da educação de surdos. O Instituto Federal de Educação, Ciência e Tecnologia de Goiás (2015) já oferta graduação em Pedagogia Bilíngue e de acordo com o exposto no site o curso de Licenciatura em Pedagogia Bilíngue:

Tem como objetivo principal a formação do educador bilíngue, que ao final do curso esteja apto a trabalhar com a educação de alunos surdos e ouvintes, atendendo a todos em sua primeira língua e com metodologias de ensino adequadas a ela. Sua formação compreenderá os níveis de ensino, gestão e pesquisa. [...] 0 profissional licenciado em Pedagogia Bilíngue torna-se apto para atuar nas seguintes áreas, todas envolvendo pessoas surdas e ouvintes:

- Docência na Educação Infantil e nos anos iniciais do Ensino Fundamental, nos cursos de Ensino Médio, na modalidade Normal, e em cursos de Educação Profissional na área de serviços e apoio escolar, bem como em

outras nas quais sejam previstos conhecimentos pedagógicos,

- Trabalho em espaços escolares e não escolares,

- Pesquisa,

- Outras áreas explicitadas pela Classificação Brasileira de Ocupações (CBO), como coordenador pedagógico, orientador educacional, professor de técnicas e recursos audiovisuais, supervisor de ensino e/ou designer educacional.

Dessa forma, a Pedagogia Bilíngue traz contribuições positivas para a educação de surdos por preparar profissionais coerentes com as exigências da mesma. 


\section{CONSIDERAÇÕES FINAIS}

Esse artigo foi elaborado para pesquisar e discutir sobre as possíveis contribuições da Pedagogia Bilíngue para a educação de surdos. Com as análises bibliográficas, concluiuse que a Pedagogia Bilíngue traz resultados positivos para a educação de surdos através da formação de profissionais qualificados para esta área.

Os conhecimentos adquiridos no decorrer da formação acadêmica em Pedagogia Bilíngue estarão respondendo as necessidades e especificidades dos surdos de forma que aconteçam aprendizagens eficientes e eficazes, oferecendo acesso e qualidade à comunidade surda.

Para chegar a esse ponto, foi preciso compreender conhecer o sujeito surdo e reconhecer que a comunidade surda possui sua própria língua, sua cultura e identidade. Além disso, as especificidades e dificuldades do aluno surdo tambémforam apresentadas no texto. A comparação entre as grades curriculares de graduação em Pedagogia e em Letras/ Libras também foram fundamentais para perceber os conhecimentos semelhantes e diferentes e entender a importância da graduação em Pedagogia Bilíngue para a comunidade surda. Esta sim possuiria conhecimentos de acordo com as necessidades da área e levaria em consideração parte dos conhecimentos de Pedagogia e parte dos conhecimentos de Letras/Libras.

Este artigo é mais um subsídio para o estudo da Pedagogia Bilíngue e que pode suscitar novas pesquisas e artigos. Afinal, falar em Pedagogia Bilíngue ainda é uma novidade no campo do ensino superior e tem muito a ser descoberta.

\section{REFERÊNCIAS}

BEHARES, L. E. Novas correntes na educação do surdo: dos enfoques clínicos aos culturais. Santa Maria: UFSM, 2000. 


\section{CAPOVILLA, F. C.; RAPHAEL, W. D. Dicionário enciclopédico ilustrado trilíngue}

- Língua de Sinais Brasileira Libras. Vol. I e II. 2. ed. São Paulo: Ed. Universidade de São Paulo, 2001.

CORMEDI, M. A. Estudos sobre a deficiência auditiva e surdez. 2011. Brasília - DF. Disponível em: <http://lms.ead1.com.br/webfolio/Mod6625/estudos sobre_a_deficiencia_auditiva_e_surdez_v2.pdf>. Acesso em:26. mar.2016.

DAMÁZIO, M. F. M. Atendimento Educacional Especializado. São Paulo: MEC/ SEESP, 2007.

FERNANDES, S. Educação de Surdos. 2 ed.atual. Curitiba: Ibpex, 2011.

GIL, A. C. Como elaborar projetos de pesquisa. 4. ed. 9. reimpr. São Paulo: Atlas, 2007.

INSTITUTO FEDERAL DE EDUCAÇÃO, CIÊNCIA E TECNOLOGIA. Pedagogia Bilíngue apresentação. Goiânia- GO Disponível em: <http://www.aparecida.ifg. edu.br/index.php/licenciatura-em-pedagogia-bilingue>. Acesso em: 26. mar. 2016.

LOPES, M. C. A natureza educável do surdo: a normalização surda no espaço da escola de surdos. In: THOMA, A. S.; LOPES, M. C.(Org). A invenção da surdez: cultura, alteridade, identidade e diferença no campo da educação. Santa Cruz do Sul: EDUNISC, 2005.

NASCIMENTO, S. P. de F. do; COSTA, M. R. Movimentos surdos e os fundamentos e metas da escola bilíngue de surdos: contribuições ao debate institucional.In: Educar em Revista. Dossiê Educação Bilíngue para Surdos: Políticas e Práticas. Ed. Especial N.2/2014. Curitiba: Ed. UFPR, 2014.

QUADROS, R. M.; KARNOPP, L. B. Língua de sinais brasileira. Estudos lingüísticos. Porto Alegre: Artmed; 2004. 
SCHEIBE, L. Diretrizes Curriculares para o curso de pedagogia: trajetória longa e inconclusa. Cadernos de Pesquisa v. 37, n. 130, jan./abr. São Paulo: 2007, p. 43-

62. Disponível em: <http://www.scielo.br/scielo.php?script=sci_arttext\&pid=S0 100$15742007000100004>$. Acesso em: 26. mar. 2016.

SKLIAR, C. Perspectivas políticas e pedagógicas da educação bilíngue para surdos. In. SILVA, S. e VIZIM, M. (org). Educação especial: múltiplas leituras e diferentes significados. Campinas, SP: Mercado de Letras: Associação de Leitura do Brasil - ALB, 2001, p. 85-107.

STROBEL, K. As imagens do outro sobre a cultura surda. 2. ed. rev. Florianópolis: Ed. da UFSC, 2009. UNIVERSIDADE FEDERAL DE SANTA CATARINA. Vestibular UFSC/2015 Letras/Libras. Disponível em:<http://www.vestibular2015.ufsc.br/letraslibras/>. Acesso em: 26. mar. 2016.

Curso de Pedagogia - Currículo em implantação progressiva a partir de 2009. Disponível em: <http://pedagogia.ufsc.br/files/2013/07/matriz_curricular 2009.pdf>. Acesso em: 26. mar. 2016.

Curso de Letras/Libras Língua Brasileira de Sinais Licenciatura - Currículo

do curso. Disponível em: <http://cagr.sistemas.ufsc.br/relatorios/curriculo Curso?curso $=440 \&$ curriculo $=20092>$. Acesso em: 26. mar. 2016. 
Quadro 1 - COMPARATIVO CURRICULAR DE PEDAGOGIA E LETRAS/LIBRAS

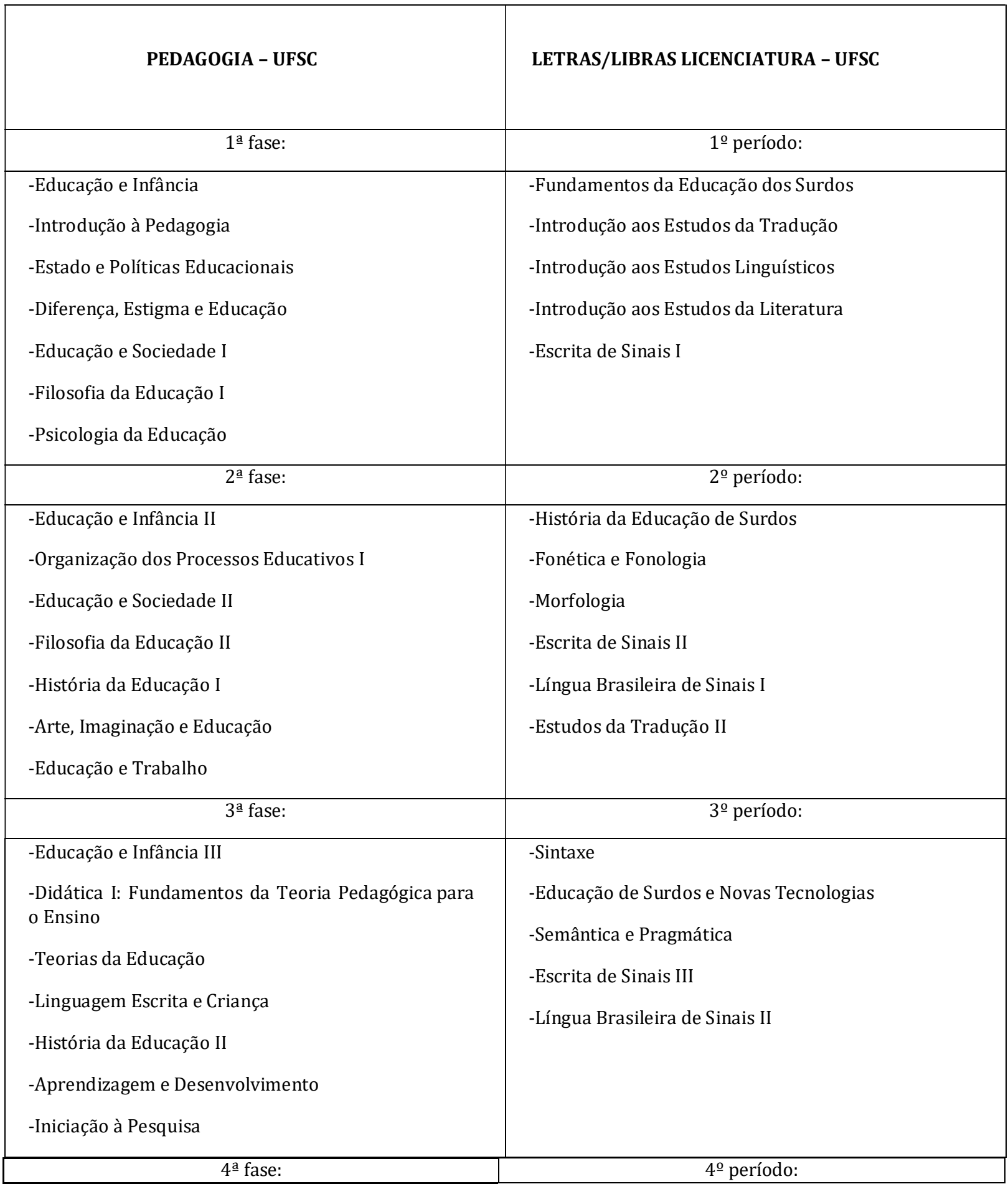




\begin{tabular}{|c|c|}
\hline $\begin{array}{l}\text { Educação e Infância IV: Fundamentos da } \\
\text { Educação Infantil } \\
\text {-Organização dos Processos Educativos II } \\
\text {-Alfabetização } \\
\text {-Ciências, Infância e Ensino }\end{array}$ & $\begin{array}{l}\text {-Aquisição de Linguagem } \\
\text {-Sociolinguística } \\
\text {-Teoria da Educação e Estudos Surdos } \\
\text {-Educação Bilíngue } \\
\text {-Língua Brasileira de Sinais III }\end{array}$ \\
\hline $\begin{array}{l}5^{\text {a }} \text { fase: } \\
\end{array}$ & 5o período: \\
\hline $\begin{array}{l}\text { Educação e Infância V: Conhecimento, Jogo, } \\
\text { Interação e Linguagens I } \\
\text {-Organização dos Processos Educativos na } \\
\text { Educação Infantil I } \\
\text {-Literatura e Infância } \\
\text {-Cenorafia_Infância e Ensino } \\
6^{\underline{a} \text { fase: }}\end{array}$ & $\begin{array}{l}\text {-Análise do Discurso } \\
\text {-Didática e Educação de Surdos } \\
\text {-Leitura e Produção de Textos } \\
\text {-Linguística Aplicada ao Ensino de Línguas } \\
\text {-Língua Brasileira de Sinais IV }\end{array}$ \\
\hline $\begin{array}{l}\text {-Educação e Infância VI: Conhecimento, Jogo, } \\
\text { Interação e Linguagens II } \\
\text {-Organização dos Processos Educativos na } \\
\text { Educação Infantil II } \\
\text {-Políticas e Práticas Pedagógicas Relacionadas à } \\
\text { Educação Especial } \\
\text {-Língua Portuguesa e Ensino } \\
\text {-Infância e Educacão do Corpo } \\
7 \text { ạ fase: }\end{array}$ & $\begin{array}{l}\text {-Tradução e Interpretação da Língua de Sinais } \\
\text {-Psicolinguística } \\
\text {-Estudo de Língua Materna } \\
\text {-Literatura Surda } \\
\text {-Língua Brasileira de Sinais V }\end{array}$ \\
\hline $\begin{array}{l}\text { Educação e Infância VII: Estágio em Educação } \\
\text { Infantil } \\
\text {-Língua Brasileira de Sinais I } \\
\text {-Comunicação e Educação }\end{array}$ & $\begin{array}{l}\text {-Metodologia do Ensino em Língua Brasileira de } \\
\text { Sinais como L1 } \\
\text {-Metodologia do Ensino em Língua Brasileira de } \\
\text { Sinais como L2 } \\
\text {-Metodologia do Ensino em Literatura Surda }\end{array}$ \\
\hline 8- fase: & $8^{\circ}$ período: \\
\hline $\begin{array}{l}\text {-Educação e Infância VIII: Exercício da Docência nos Anos } \\
\text { Iniciais } \\
\text {-Didática II: Processos de Ensino nos Anos } \\
\text { Inicias da Escolarização } \\
\text {-Organização dos Processos Coletivos do } \\
\text { Trabalho Escolar }\end{array}$ & $\begin{array}{l}\text {-Estágio em Literatura Surda } \\
\text {-Estágio em Língua Brasileira de Sinais como L1 } \\
\text {-Estágio em Língua Brasileira de Sinais como L2 }\end{array}$ \\
\hline $\begin{array}{l}\text {-Educação Especial: Conceitos, Concepções e } \\
\text { Sujeitos } \\
\text {-Trabalho de Conclusão de Curso }\end{array}$ & \\
\hline
\end{tabular}

Fonte: site da Universidade Federal de Santa Catarina 